\title{
The Modified Phillips Curve as a Possible Answer to Japanese Deflation
}

\author{
Noriko Ashiya \\ Faculty of Real Estate, Meikai University, Japan
}

Copyright $\bigcirc 2017$ by authors, all rights reserved. Authors agree that this article remains permanently open access under the terms of the Creative Commons Attribution License 4.0 International License

\begin{abstract}
A modified Phillips curve is useful to explain the contradictory findings sometimes arising from conventional Phillips curve estimation. In this paper, we estimate the inflation-unemployment and real wage inflation-unemployment dynamics for both Japan and the United States using data between 1972:Q1 and 2014:Q4. We divide this into two roughly equally sized sub-periods, 1972:Q1-1991:Q4 and 1992:Q1-2014:Q4. The first sub-period tracks the Japanese economic boom prior to the bursting of the bubble economy; the second continues to reflect the long recessionary period in Japan that followed. The modified Phillips curve serving as the aggregate supply (AS) curve with a quantity equation with zero velocity as the aggregate demand (AD) curve in an AS-AD framework, reveals that much of the slowdown in Japanese inflation was due to the lack of the postwar acceleration of "productivity-based" real wage inflation, a feature unexplained within a traditional demand-oriented approach. Some of the efficacy of the productivity-based real wage acceleration that we identified is related to the use of this simpler formulation of the AD curve, which even though it has an inherent analytical bias in supporting the role of monetary policy, it is permissible when focus lies on the decisions of suppliers.
\end{abstract}

Keywords Phillips Curve, AS-AD Analysis, Monetary Policy, Deflation

\section{Introduction}

The slope of the Phillips curve has become flatter in the past few decades, and until recently has been largely considered moribund. The watershed moment came when Gordon [1] and later Watson [2], adopted the approach of excluding long-term unemployment in reviving the negative correlation between inflation and unemployment. In this paper, we highlight another major development in the Phillips curve literature in the reformulation of the productivity variable as an eight-quarter change in the productivity trend (see, Dew-Becker and Gordon [3]). This seems to have greatly contributed to the reemergence of the Phillips curve relation in 2013, with the estimation results in Gordon [1] indicating that this rather unfamiliar productivity measure exerts significant upward pressure on the U.S. inflation rate (see Table A1). ${ }^{1}$ However, in examining Fig. A1, we can see that for Japan, the working of this new measure of productivity is rather uncertain. Gordon's ideal model setting that allows the nonaccelerating inflation rate of unemployment (NAIRU) to vary over time does not work as predicted and leads to very flat NAIRUs. Therefore, on further examination, we fix the value of the variance of the NAIRU, the simplest way being to adopt a constant NAIRU setting, which provides the first approach to estimating the Japanese Phillips curve. $^{2}$

Critically, we find the estimation results of the Phillips curve with a constant NAIRU setting to be contradictory (see Table 1). In our analysis, we find the sign of the regression coefficient for the productivity variable to be positive for an earlier period, although weakly so. In contrast, the ordinary Phillips curve is negative for this same period. The question is why this is the case and we believe the answer may well provide a remedy to the current problem of deflation in Japan. This paper is thus our attempt to provide empirical evidence and corresponding theoretical underpinnings to support this assertion.

Therefore, in this paper, we formulate a modified Phillips curve relation and use this to reevaluate the above findings. We find that the modified Phillips curve (aggregate supply [AS] curve), in conjunction with a quantity equation with constant velocity equals zero (aggregate demand [AD] curve), reveals that much of the slowdown in Japanese

\footnotetext{
1 Gordon [1] revealed that the new index of productivity dramatically improves the explanatory power of the inflation equation for the Phillips curve.

2 The constant NAIRU setting can also be justified by OECD-sponsored studies of various countries (see, e.g., the study of 21 OECD countries by Richardson et al. [4] and OECD update after 2008 by Guichard and Rusticelli [5]); which is also in line with prior research on Japan's Phillips curve undertaken by Nishizaki [6]. For unsatisfactory outcomes from the time-varying NAIRU model, see, e.g., Apel and Jansson [7] and Laubach [8]
} 
inflation is because of the lack of the postwar acceleration of "productivity-based" real wage inflation not explained within a traditional demand-oriented formulation. Part of the efficacy of productivity-based real wage acceleration we identify is related to this simpler formulation of the $\mathrm{AD}$ curve, which has an inherent analytical bias in supporting the role of monetary policy, although this is permissible when focus is on the decisions of suppliers (see, e.g., Lucas [9] for a justification).

The literature relating to this paper dates back to analysis conducted during the rapid growth period in Japan. In 1986, Hamada and Kurosaka [10] shifted the emphasis from downward wage rigidity to upward wage flexibility. Comparing Japanese data with that of the U.S. and three other countries, they highlighted the upward volatility of wages in Japan - a feature consistent with the commonly held view of the Japanese labor market. This could also be a way for us to include wages in Gordon's triangular Phillips curve, creating a modified Phillips curve. In fact, Hamada and Kurosaka's findings on the Japanese labor market that real wage flexibility accommodates productivity changes during the period 1971-75 and, until 1983, is consistent with the real wage-setting function we include as a missing element in the standard (triangular) Phillips curve equation. In contrast, Kuroda and Yamamoto [11] have focused on downward, not upward, wage flexibility. They also decomposed the change in the nominal rather than the real wage. The quasi-Phillips curve they plotted suggests a malfunctioning of the Japanese labor market in recent years, and is consistent with the approach taken in this paper.

The standard Phillips curve equation also appears in Nishizaki et al. [12], which indicates that a decline in price expectations and import prices, the negative output gap, and a higher exchange rate all account for long-lasting, mild deflation. Ashiya's [13] analysis also provides preliminary insights into the price dynamics, which we extend in a more general framework using Okun's coefficient (see Appendix B). We extend this Phillips curve relation to an AS relationship, which when combined with the $\mathrm{AD}$ curve provides a theoretical underpinning for the behavior of price and output in the Japanese economy, and thereby helps to explain the slowdown in inflation. We maintain the generality of Ashiya's findings on the role of price expectations in the postwar (mature) Japanese economy in our $\mathrm{AS}-\mathrm{AD}$ framework.

In a somewhat different analysis, Sudo et al. [14] used daily scanner price data to decompose the price changes to find that retail shops (or suppliers) play an important role in Japanese price dynamics. This focus on suppliers supports our emphasis on the supply side of the economy. Our findings are also close to Urasawa [15] in that the translation of productivity gains into adequate wage growth and demand may help resolve Japanese deflation. Urasawa estimates a structural vector auto regressive model using productivity, wage costs, and prices, similar in many ways to the modified Phillips curve we extend to an $\mathrm{AS}-\mathrm{AD}$ framework. We reasonably expect the acceleration of productivity-based real wage inflation in the postwar boom economy, but that this will become increasingly more difficult in Japan's currently mature economic state. One consequence is that the role of economic policy in externally affecting price expectations has become more significant, exactly as the modified $\mathrm{AS}-\mathrm{AD}$ equilibrium suggests.

The remainder of the paper is structured as follows. Section 2 details the formulation of the model and Section 3 discusses the data. Section 4 presents the estimation results and Section 5 elaborates upon the theoretical underpinnings. Section 6 concludes. In Appendix A, we summarize the estimation results of the Phillips curve model with the time-varying NAIRU setting and in Appendix B we do the same for Okun's coefficient.

\section{Estimation Models}

The estimation models for the inflation-unemployment dynamics (Phillips curve) and the real wage inflationunemployment dynamics (quasi-Phillips curve) are as follows. To estimate these constant NAIRU models, it is adequate to use ordinary least squares (OLS), where we calculate the NAIRU, $U_{t}^{N}$, as $\alpha=-\beta_{2} U_{t}^{N}$ in (1). The specification and estimation results of the time-varying NAIRU model are in Appendix A.

\section{Model 1 (Phillips curve equation with constant NAIRU setting)}

$$
\begin{gathered}
\pi_{t}=\alpha+\sum_{i=1}^{4} \beta_{i} \pi_{t-i}+\gamma U_{t}+\sum_{i=0}^{3} \delta_{1} \text { energy }_{t-i}+ \\
\delta_{2} \operatorname{prod}_{t}+\varepsilon_{t}
\end{gathered}
$$

where $\pi_{t}$ denotes the level of price inflation, $U_{t}$ the unemployment rate, energy $y_{t}$ energy prices, $\operatorname{prod}_{t}$ productivity, and $\varepsilon_{t}$ is the error term.

Our specification follows the reasoning in Gordon [1]. We adopt four lags for the dependent variable, $\pi_{t}$ and three lags for energy, energy $y_{t}$, all of which could specify a small amount of price inertia. The level of price inflation is then included using four terms in each sigma component. The productivity variable $\operatorname{prod}_{t}$ is the eight-quarter change in the trend rate of productivity growth (see, Gordon [1], Dew-Becker and Gordon [3]) and already smoothed, which is why we omit the lags for this variable.

In a general form, we specify the model as:

$$
\pi_{t}=\beta(L) \pi_{t-1}+\gamma(L)\left(U_{t}-U_{t}^{N}\right)+\delta(L) Z_{t}+\varepsilon_{t},
$$

where $Z_{t}$ denotes the additional supply-shock variables, and $\beta(L), \gamma(L)$ and $\delta(L)$ are the lag-polynomials that specify the dynamics of the price behavior. For details, see Gordon [1], [16], and [17].

To obtain (1), we first specify the lag lengths and polynomials and the supply-shock variable as:

$$
\begin{gathered}
\pi_{t}=\sum_{i=1}^{4} \beta_{i} \pi_{t-i}+\gamma\left(U_{t}-U_{t}^{N}\right)+\sum_{i=0}^{3} \delta_{1} \text { energy }_{t-i}+ \\
\delta_{2} \operatorname{prod}_{t}+\varepsilon_{t} .
\end{gathered}
$$


Then we assume that $U_{t}^{N}$, NAIRU, is constant. With this assumption, we can extract $U_{t}^{N}$ from $\gamma\left(U_{t}-U_{t}^{N}\right)$ in (3) to obtain the portion $-\gamma U_{t}$. We then substitute $\alpha$, a constant term, for this extracted portion, $-\gamma U_{t}^{N}$, to transform (3) into (1), a simpler form of the Phillips curve equation with constant NAIRU setting.

\section{Model 2 (Quasi-Phillips curve explaining real wage-setting behavior)}

$$
\omega_{t}=\alpha+\gamma U_{t}+\operatorname{sprod}_{t}+\varepsilon_{t},
$$

where $\omega_{t}$ denotes real wage inflation. We specify the real wage-setting behavior in the simplest form, which provides us with a step to arrive at a modified Phillips curve.

We estimate both Models 1 and 2 for Japan and the United States using the data between 1972:Q1 and 2014:Q4, which is divided into two parts between 1972:Q1 and 1991:Q4 and 1992:Q1 and 2014:Q4. The first part reflects the Japanese economic boom prior to the bursting of the bubble economy, and the second part continues to track the long recessionary period that has followed. We use the beginning of 1992:Q1 as the breakpoint for this sample. See Krugman [18] for the justification.

\section{Data}

We focus on consumer price inflation. For Japan, we use the consumer price index (CPI) data for all consumers and all items excluding fresh food, which is the targeted index (from 2013:Q2) or guide index (up to 2013:Q1) for the inflationary trend the Bank of Japan tracks. For the U.S. we use CPI data for only urban consumers, which means that fresh food prices are included, but unfortunately not all areas of the U.S. are surveyed, even though it is the most relevant variable for our comparison (see, Figs 1 and 2).

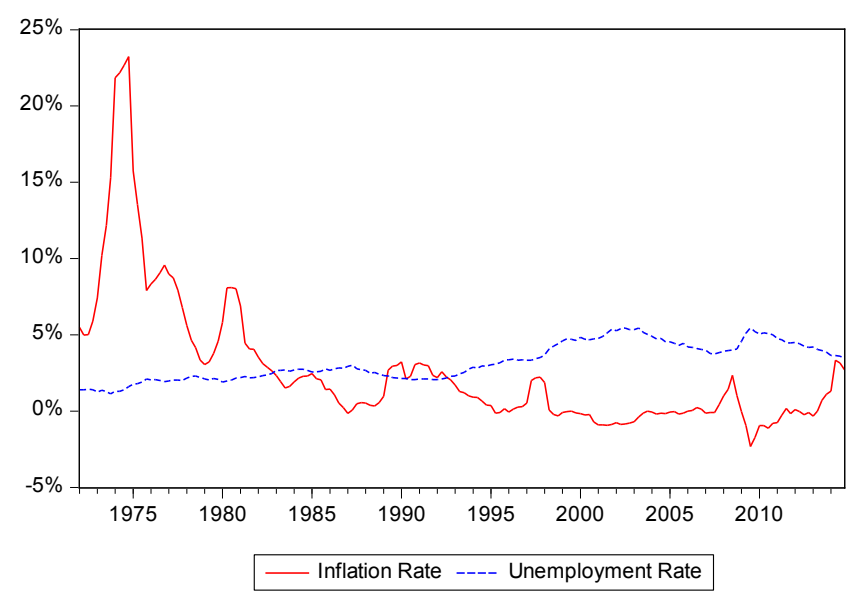

Figure 1. Headline Inflation and Total Unemployment Rates (Japan), 1972:Q1 to 2014:Q4

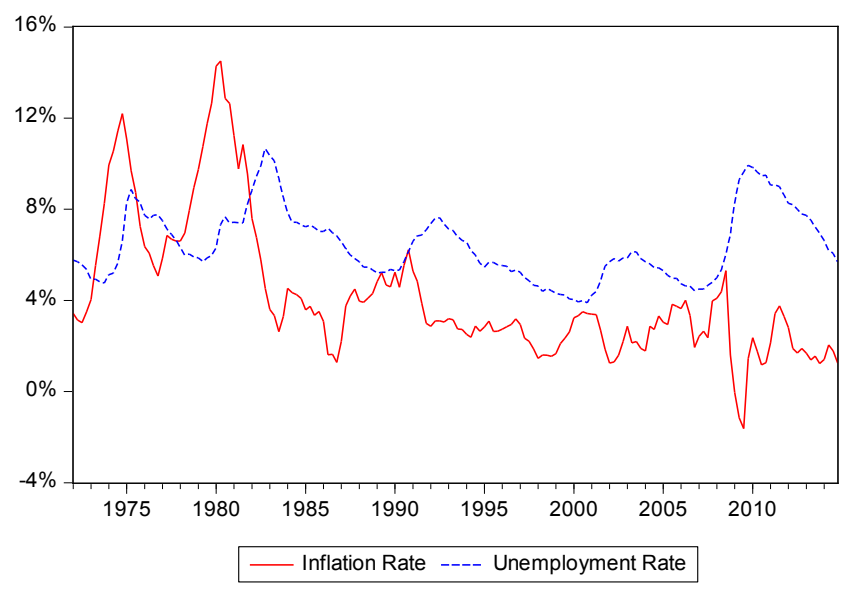

Figure 2. Headline Inflation and Total Unemployment Rates (U.S.), 1972:Q1 to 2014:Q4

To emphasize firm price- and wage-setting behavior as represented by the Phillips curve (see Section 5) we do not subtract the inflationary effects of the sales tax hike from both CPI series. Consequently, we can compare the estimation results for Japan and the U.S. We support this in that firms rationally consider the upward pressure of sales tax hikes on wages and prices. Moreover, the economic logic behind the Phillips curve also supports the use of these CPIs.

All data are quarterly, which coincides with the frequency of the release of the national accounts (particularly GDP used in the calculation of new productivity). The raw price inflation data for Japan is the percentage change in CPI from the same month one year previously, and, for the U.S., the seasonally adjusted monthly series of CPI, which we convert into percentage changes. Consequently, in this paper, we estimate the relationship between the percentage change in CPI and the level of unemployment, unlike Gordon's work, which employs the first differences in the logarithm of CPI. We mainly follow Gordon [1] in most aspects of our analysis, but attempt to improve the performance of our models using the percentage change not the logarithm of CPI.

We also specify total unemployment, not unemployment excluding long-term unemployment as in Gordon [1]. The reason is that the short-run unemployment data for the U.S. is very similar in definition to that for Japanese total unemployment ${ }^{3}$. We source the Japanese unemployment rate from labor statistics and that for the U.S. from the current employment statistics. As the raw data are monthly, we adjust them to their quarterly values to make them consistent in frequency to productivity, for which we specify quarterly data (particularly for GDP) extracted from the national accounts. This is also consistent with the frequency of the

3 The level and variance of unemployment in Japan is generally quite small. See, e.g., pioneering work by the U.S. Department of Labor [19] and Shiraishi [20], and the review in Hamada and Kurosaka [21]. By contrast, for U.S. unemployment, Cao and Shapiro's [22] decomposition clearly shows that the variance of short-run unemployment, which they obtain by excluding long-run unemployment from total unemployment, has been relatively small. From the viewpoint of variance, Japanese total unemployment and U.S. short-run unemployment seem very close by definition, and therefore play similar roles in Phillips curve estimation. 
data we collect for inflation and unemployment as described above.

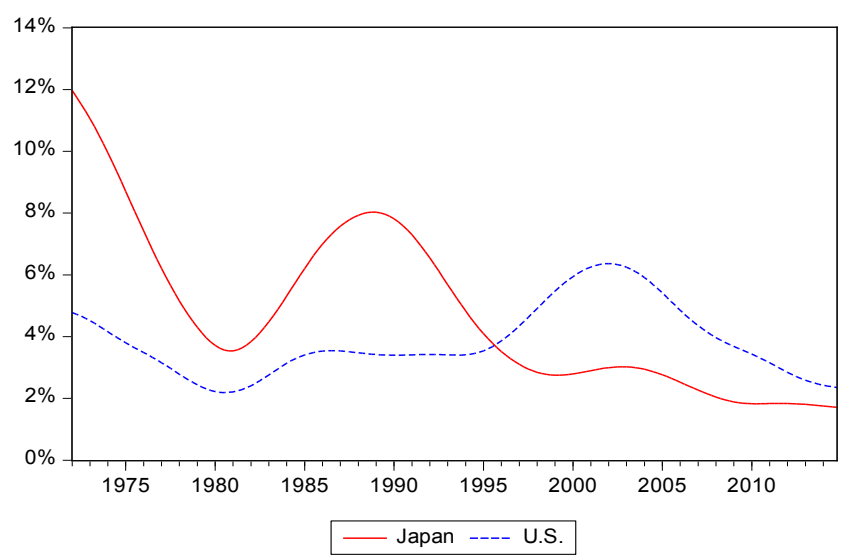

Figure 3. Eight-Quarter Change in Productivity Trend (Japan and U.S.), 1972:Q1 to 2014:Q4

Productivity, which is the focus of this analysis, is also as per Gordon [1]. We define productivity as the productivity trend growth acceleration variable, which is the Hodrick-Prescott filtered trend in productivity growth (using 6400 as the smoothness parameter) minus the same trend eight quarters earlier (see, Dew-Becker and Gordon [3]). For the same reason as the CPI variables, we specify the productivity trend as percentage changes not logarithms (see Fig. 3).
The energy variable we specify is also consistent with Gordon's [1] methodology and is the energy CPI for Japan and the U.S., both from the OECD database. The same database provides the average hourly wage index, for both Japan and the U.S., as the real wage variable.

\section{Estimation Results}

Tables 1 and 2 provide the estimates of the inflationunemployment and real wage inflation-unemployment dynamics using Models 1 and 2, respectively. Both tables reflect our focus on the effects of the productivity variable.

The estimates in Table 1 illustrate two remarkable results. One is the difference in productivity effects that arise in the first and second periods for both countries and the other is the difference in results between Japan and the U.S. The third column in Table 1 reports the estimates for Japan for the period between 1972:Q1 and 1991:Q4, with a positive regression coefficient of the productivity variable (3.014), which, although weak, lies contradictory to the price theory represented by the Phillips curve. Furthermore, in the succeeding period between 1992:Q1 and 2014:Q4, the coefficient on the productivity variable in the fifth column has become negative $(-0.575)$.

Table 1. Estimation Results of the Phillips Curve Equation (Constant NAIRU Setting), Model 1, 1972:Q1 to 2014:Q4

\begin{tabular}{|c|c|c|c|c|c|c|c|c|c|}
\hline \multirow{2}{*}{ Variable } & \multirow[t]{2}{*}{ Lags } & \multicolumn{3}{|c|}{ 1972:Q1-1991:Q4 } & \multicolumn{5}{|c|}{ 1992:Q1-2014:Q4 } \\
\hline & & Japan & & U.S. & & Japan & & U.S. & \\
\hline Constant & & $3.036(2.1)$ & *** & $2.775(3.4)$ & **** & $0.690(1.9)$ & * & $1.958(2.8)$ & *** \\
\hline Lagged Dependent Variable & $1-4$ & $0.848(14.2)$ & $* * *$ & $0.798(19.5)$ & $* * *$ & $0.808(12.8)$ & $* * *$ & $0.566(4.7)$ & $* * *$ \\
\hline Unemployment Rate & 0 & $-1.151(2.4)$ & $* *$ & $-0.163(2.6)$ & $* *$ & $-0.161(2.4)$ & $* *$ & $-0.109(2.2)$ & $* *$ \\
\hline Productivity Trend Change & 0 & $3.014(0.5)$ & & $-23.752(1.8)$ & $*$ & $-0.575(0.1)$ & & $-11.862(2.0)$ & $*$ \\
\hline Energy Effect & $0-3$ & $0.014(0.8)$ & & $21.740(4.4)$ & $* * *$ & $0.031(2.6)$ & $* *$ & $25.091(4.6)$ & $* * *$ \\
\hline Adjusted R-Squared & & 0.97 & & 0.97 & & 0.97 & & 0.97 & \\
\hline Standard Error of Regression & & 0.96 & & 0.53 & & 0.96 & & 0.53 & \\
\hline Sum of Squared Residuals & & 63.22 & & 19.33 & & 63.22 & & 19.33 & \\
\hline
\end{tabular}

Notes: OLS estimates with heteroscedasticity and autocorrelation consistent (HAC) standard errors and covariance (Bartlett kernel, Newey-West fixed bandwidth $=4.0000$ ). t-statistics in parentheses. $* * *$, and $* * *$ indicate coefficient or sum of coefficient is statistically significant at the 10,5 , or 1 percent level, respectively. As shown, the estimated coefficient for Gordon's [1] productivity variable fits the U.S. Phillips curve well at the 10 percent level with a large magnitude.

Table 2. Real Wage-Setting Equation (Quasi-Phillips Curve Equation), Model 2, 1972:Q1 to 2014:Q4

\begin{tabular}{|c|c|c|c|c|c|c|c|c|}
\hline \multirow[t]{2}{*}{ Variable } & & \multicolumn{4}{|c|}{ 1972:Q1-1991:Q4 } & \multicolumn{3}{|c|}{ 1992:Q1-2014:Q4 } \\
\hline & & \multicolumn{2}{|c|}{ Japan } & \multicolumn{2}{|c|}{ U.S. } & \multicolumn{2}{|c|}{ Japan } & U.S. \\
\hline Constant & & 0.047 & $(4.1) * * *$ & 0.013 & $(0.2)$ & 0.018 & $(3.0) * * * 0.013$ & $(4.8) * * *$ \\
\hline Unemployment Rate & 0 & -0.021 & $(5.9) * * *$ & 0.000 & $(0.4)$ & -0.004 & $(3.6) * * *-0.001$ & $(3.7) * * *$ \\
\hline Productivity Trend Change & 0 & 0.239 & $(3.3) * * *$ & 0.017 & $(0.9)$ & -0.105 & -0.001 & $(0.0)$ \\
\hline Energy Effect & $0-3$ & 0.000 & $(1.7)$ & 0.000 & $(6.7) * *:$ & 0.000 & 0.000 & $(0.1)$ \\
\hline Adjusted R-Squared & & 0.43 & & 0.44 & & 0.16 & 0.38 & \\
\hline Standard Error of Regression & & 0.02 & & 0.39 & & 0.01 & 0.00 & \\
\hline Sum of Squared Residuals & & 0.02 & & 0.00 & & 0.01 & 0.00 & \\
\hline
\end{tabular}

Notes: OLS estimates with HAC standard errors \& covariance (Bartlett kernel, Newey-West fixed bandwidth $=4.0000$ ). t-statistics in parentheses. *, **, and *** indicate coefficient or sum of coefficient is statistically significant at the 10,5 , or 1 percent level, respectively. The results represent the additional productivity effects on the real wage-setting behavior of the firm. The dependent variable is the rate of change in the average hourly earnings index (MEI) extracted from the OECD database. The presence of productivity-based real wage acceleration is suggested for Japan in the first period (1972:Q1 to 1991:Q4), which reveals that the productivity variable may have been exerting upward pressure on real wage inflation. In the same period, the regression coefficient of the original Phillips curve for the same productivity variable is weakly positive. For Model 3 (quasi-Phillips curve model), we select the change in the index of average hourly earnings (MEI) from the OECD database as the measure of real wage inflation. 
We fail to reject the hypothesis that the coefficient on the productivity trend change in (1) is zero even at the $10 \%$ level in both periods for Japan. However, the U.S. results (also reported in Table 1), combined with supporting evidence on the productivity effects that exert upward pressure on the real wage rate (see the third column in Table 2), suggest that the upward shift in the real wage-setting function took place in the first period. We discuss this later in terms of the specification of real wage-setting function.

In terms of the magnitude of the effects in Table 1, the productivity effects on inflation are very high for the U.S. ( -23.752 in the first period and -11.862 in the second) relative to those for Japan (3.014 and -0.575). This relationship reverses in Table $2 .{ }^{4}$ Simply put, the productivity effects on real wage inflation for the U.S. are relatively small when compared with the effects on price inflation, and almost seem to almost disappear $(-0.001)$ in the second period (sixth column in Table 2), although not significantly. Conversely, for Japan these effects seem to be become weaker in the second period $(-0.105)$, but are still significant.

Importantly, the third column in Table 2 shows evidence of significant productivity growth for Japan in the period between 1972:Q1 and 1991:Q4. It begins with positive and dramatic growth in the early 1970 s, and then the slow growth period of the oil crises of 1973 and 1979, the yen/dollar appreciating after the Plaza Accord of 1985, and the growth associated with the "bubble" economy. This thus reveals a certain level of pass-through effects of the productivity trend change on real wage inflation in the postwar Japanese economy. In the next section, we model thus as the real wage-setting function and incorporate it into our modified Philips curve.

The remaining results are as follows. First, as shown in the fourth and sixth columns in Table 1, the U.S. displays a weak negative relationship between inflation and unemployment. Comparing the U.S. and Japan for the first period, the magnitude of this relationship is -0.163 for the U.S. and 1.151 for Japan. The Phillips curve correlation for the U.S. is then only about one-tenth of that for Japan before the bubble economy burst. In contrast, in the second period the two countries are much closer although still with a negative relationship, -0.109 for the U.S. and --0.161 for Japan. As shown, the Phillips curve analysis reveals a dramatically reduced reaction of price in relation to a decrease in unemployment in Japan, resulting in an estimate for the second period similar to that in the U.S. Second, as shown in both Tables 1 and 2, the energy effects are weak and this is consistent with the findings in Blanchard and Galí [23] who note the declining pass-through effects of changes in energy or oil prices on overall inflation. The magnitude of these extremely low for Japan compared to the U.S., which likely reveals the international differences in resource endowment (e.g., oil) and relates to the insights in Bruno [24].

\section{Theoretical Underpinnings for Seemingly Contradictory Results}

In this section, we formulate a modified Phillips curve theory and use this to explain the contradictory findings in Gordon [1]. The new theory includes supporting evidence on the real wage behavior. We also extend this to a more general form of the AS curve, which, in conjunction with the AD curve, yields a modified AS-AD framework.

\subsection{General Settings}

Our theoretical model adopts a conventional production function with diminishing returns, which without any additional settings would generate the countercyclical movement of real wages - as employment increases (or conversely, the unemployment rate decreases), the real wage rate decreases (see Akerlof et al. [25], and comments by Mankiw [26] on this). ${ }^{5}$ Importantly, this fact counters our empirical findings (see Table 1), although our results are limited to the specific period between 1972:Q1 and 1991:Q4, In this period, we confirmed the contradictory findings for Japan's Phillips curve, and also found a cyclical real wage, which increases as employment/output increases.

We start by specifying the real wage-setting function, $w_{t}\left(U_{t}, G_{t}, E_{t}\right): w_{t}=\left(G_{t}^{\alpha} / U_{t}\right) E_{t}$. This incorporates the empirical economic characteristics into our theoretical analysis in its simplest triangular form. The term $w_{t}$ denotes the real wage rate and $E_{t}$ the rate of change in energy prices. We assume that real wage inflation is sensitive to the business cycle, and is affected by imperfections in both labor and product markets. The term $G_{t}^{\alpha}$ works as a productivity-based factor with an external accelerator $\alpha$, which governs the magnitude of $G_{t}^{\alpha}$. The term $1 / U_{t}$ represents downward wage rigidities. More precisely, as $U_{t}$ increases, the rate of decrease in $w_{t}$ declines. $E_{t}$, energy, is multiplied against these two factors.
4 Using a time-varying NAIRU setting, Gordon [1] argued that this productivity effect had a minor (but noticeable) influence (see Table 1 in Gordon [1], pp. 24), which is more consistent with our estimation results in Table A1 in Appendix A. However, we do not consider further the difference in results between the time-varying and constant NAIRU models.
5 Under the assumption of diminishing returns technology, the implied relationship between unemployment and output becomes nonlinear and concave to the origin. However, if $\alpha>1$ holds, we could expect that any acceleration will be on real wage inflation, so there will not be diminishing returns. 
Table 3. The Relationship between Productivity and Real Wage Inflation Governed by the "Accelerator"

\begin{tabular}{lccc}
\hline \multicolumn{1}{c}{ Variable } & \multicolumn{2}{c}{ Range of $\alpha$} \\
\hline Real-Wage Accerelator & $\alpha$ & $0<\alpha<1$ & $1<\alpha$ \\
Effects on Real Wage Rate & $G_{t}^{\alpha}$ & decreasing & increasing \\
Sign of Productivity Coefficient (Model 1) $\delta_{2}$ & negative $(-)$ & positive $(+)$ \\
\hline
\end{tabular}

Notes: Despite these unsatisfactory findings, our focus is on the sign of the regression coefficient of the productivity variable. Furthermore, we do not discard such an insignificant and contradictory finding on the productivity coefficient. The reason is that we take this as a reflection of the overall economy over time and not as any changes for the specific estimation period between 1972:Q1 and 1991:Q4, which corresponds to the first part of our sample period.

As emphasized, the term $G_{t}$ (Dew-Becker and Gordon-type productivity trend change) may coincide with the slope of the production function at the marginal level; this is the marginal product of labor, which may coincide with the real wage rate. Therefore, we specify $G_{t}$ as the base of the productivity effect on the real wages, and combine it with $\alpha$, a positive parameter that increases the acceleration of real wage rates. We assume that as $\alpha$ increases, $w_{t}$ results in more upward pressure; the $\alpha$-governed shifts of the real wage-setting function is included in nonlinear form (see Table 3). A large $\alpha$ indicates a positive economic state, or even rapid economic growth of the economy, and $G_{t}^{\alpha}$ replicates the cyclical movement of real wages suggested by our results. The real wage sometimes becomes countercyclical (when $\alpha=0$ or $0<\alpha<1$ ), and sometimes moves cyclically with output growth (when $\alpha>1)$.

Originally, Dew-Becker and Gordon [3] introduced the new definition of the productivity variable to improve the tracking of the effects of productivity growth (see Gordon [1]). However, we use the same variable to arrive at the simplest possible understanding of the Japanese Phillips curve. By replacing marginal labor productivity with $G_{t}$, the new measure of productivity (or marginal product of labor), makes it possible for us to extend the textbook specification into a specific framework that could help us explain Japanese deflation. Related work by Akerlof et al. [25] adopts the ordinary definition of the same variable (labor productivity) to explain the U.S. data, but as we found using the triangular model in Table 2, the U.S. evidence does not generate a contradictory (positive) productivity coefficient.

These specifications allow the $G_{t}^{\alpha}$ term to work as a productivity-related real wage accelerator. However, this holds only if the parameter $\alpha$ is sufficiently large, and the real wage-setting function as a whole shifts upwards by an amount sufficient to cancel out the downward pressure that arises from the model setting with diminishing returns. This shift, although in the context of diminishing returns, should exert the same upward drift on the Phillips curve, as confirmed by Akerlof et al. [25]. ${ }^{6}$

\subsection{The Derivation of the Phillips Curve}

One of the usual ways to derive a Phillips curve is to

6 They did so under the assumption of constant returns, and the additional term that specifies the shift in expected unit labor costs arising from downward wage rigidity. consider the actions of the representative firm and start from the firm's profit-maximizing behavior. Therefore, we first consider the simplest possible behavioral assumption, namely, the representative firm model in a single competitive market. Within this setting, we do not consider the difference between absolute and relative prices. Later, we extend this to a more conventional setting within a monopolistically competitive market.

Therefore, the first equation we consider is the demand for labor by profit-maximizing competitive firms, which corresponds to the first postulate of classical theory as follows:

$$
W_{t}=p_{t} f^{\prime}\left(n_{t}\right),
$$

where $W_{t}$ denotes the money wage rate, $p_{t}$ the price of the firm's output, and $n_{t}$ the labor unit. The term $f^{\prime}\left(n_{t}\right)$ is the derivative of the production function $f\left(n_{t}\right)$, or the marginal product of labor. Then, with the use of price expectations, we transform (4) into the price-setting equation as follows:

$$
p_{t}=\frac{p_{t}^{e} w_{t}}{G_{t}}
$$

where $p_{t}^{e}$ denotes the expected price level and $w_{t}$ the real wage rate. We have replaced $f^{\prime}\left(n_{t}\right)$ in (4) with $G_{t}$, the Dew-Becker and Gordon-type productivity to obtain (5).

Next, we consider firm behavior in a monopolistically competitive market. The simplest way is to assume unit elastic demand for a firm's output, which is dependent on both the price of the firm's output and the average price in the economy. By introducing the markup term $m$, which is defined as $m=1+\mu$ using $\mu$, the markup rate, we extend (6) as follows:

$$
p_{t}=\frac{m p_{t}^{e} w_{t}}{G_{t}}
$$

where $m$ reflects the elasticity of demand, $\beta$, and $m=$ $\beta /(\beta-1)$. The competitive firm has $m=1$, and the firm with some market power has a markup larger than 1 or $m=\beta /(\beta-1)>1$ holds. With the assumption of unit elastic demand, we could treat $m$ as given and constant to highlight the suppliers' behavior in order to arrive at the simplest formulation of the Phillips curve equation. The above is the conventional specification, except that we replace the marginal product of labor with the new productivity variable $G_{t}$, and this becomes crucial in the explanation of our seemingly contradictory results. 


\subsection{The Modified Phillips Curve}

To derive the modified Philips curve, we include the real wage-setting function, specified above as $w_{t}=\left(G_{t}^{\alpha} / U_{t}\right) E_{t}$, in (6) as follows:

$$
p_{t}=m p_{t}^{e}\left(G_{t}^{\alpha} / U_{t}\right) E_{t} / G_{t} .
$$

Then, the modified Phillips curve, or the inflation-unemployment dynamics that our findings support, uses three steps. First, replacing $p_{t}$ (the price of the firm's output) with $P_{t}$ (the average price in the economy) in (7), and second, taking the natural $\log$ of each side of this transformed equation, third, assuming $P_{t}^{e}=P_{t-1}$ and subtracting

$$
\log p_{t-1}
$$

from both sides gives:

$$
\pi_{t}=\log m+\pi_{t}^{e}-\log U_{t}+(\alpha-1) \log G_{t}+\log E_{t},
$$

where $\pi_{t}^{e}$ denotes expected price inflation. Equation (8) suggests that if $\alpha>1$ holds, then the productivity effects from the variable $G_{t}$ (productivity) will become positive.

Recall the estimation results in Table 1. The third column in Table 1 shows the positive productivity effect. This can place upward pressure on price inflation, which corresponds to the first period between 1972:Q1 and 1991:Q4, during which there was an economic boom in Japan. This implies that Japanese inflation was once supported by the postwar acceleration of the productivity-based real wage inflation (theoretically, supported by the condition of $\alpha>1$ ); the positive real wage effect would then pass through to price inflation, resulting in the contradictory positive coefficient of the productivity variable.

Furthermore, (8) suggests the important role of price expectations. In a mature economy, it is reasonable to expect severe price competition, which results in the assumption of $m=1$. Under $m=1$, the term $\log m$ becomes zero, and thus places no pressure on the resulting price inflation. As we have already considered the role of $G_{t}$, the new productivity, in placing upward pressure on price inflation, the final variable is $P_{t}^{e}$, price expectation. As a spinoff of our theoretical examination, we arrive at the role of price expectation, which through economic policy can continue to influence even a mature economy.

\subsection{An Extension of the Modified Phillips Curve to the AS Relationship}

Now, we use (8), the modified Phillips curve, to derive the AS relation. First, we replace the term $\log U_{t}$ with $-\log Y_{t}$ in (8), based on the negative relationship between $U_{t}$, the rate of unemployment, and $Y_{t}$, the AS. This relation is implied empirically by our calculation of the Okun coefficient (see Tables A2 and A3), and theoretically by the model assumption of diminishing returns. We obtain the modified AS curve as:

$$
\pi_{t}=\log m+\pi_{t}^{e}+\log Y_{t}+(\alpha-1) \log G_{t}+\log E_{t} .
$$

Then, recall that the reported coefficient of $\log U_{t}$ is negative (see Table 1), which is consistent with classical theory, and we obtain the positive coefficient of $\log Y_{t}$. That is, the upward-slope of the AS curve is implied by the stable Phillips curve relationship. If that relationship becomes ambiguous, then the AS relationship also becomes ambiguous and suggests we cannot confirm the effects of the expansion of $\mathrm{AD}$.

\subsection{Completion of the Modified AS-AD Framework}

The modified AS curve demonstrates the role of productivity and the acceleration of productivity-based real wage inflation in the postwar Japanese economy. However, to completely understand the Japanese price dynamics, we need to introduce the AD curve. Given our emphasis on the supply side of the economy, the following simple form should be sufficient for this purpose:

$$
\log M_{t}+\log v_{t}=\log P_{t}+\log Y_{t},
$$

where $M_{t}$ denotes the money supply. This formula for the $\mathrm{AD}$ side of the economy is in the form of a quantity equation, which is consistent with Lucas [9] and subsequent studies such as e.g., Akerlof et al. [25].

To activate (10) as an AD curve, we set the normalization assumption regarding velocity $\left(v_{t}=1\right)$, or the $\log$ of velocity assumed to be zero $\left(\log v_{t}=0\right)$ as:

$$
\log P_{t}=-\log Y_{t}+\log M_{t}
$$

Then, subtracting $\log P_{t-1}$ from both sides of (11), the AD relationship is written as:

$$
\pi_{t}=-\log Y_{t}+\log M_{t}-\log p_{t-1} .
$$

The assumption of $v_{t}=1$ implies that the velocity does not affect or multiply the circulation of money. This is consistent with an economic state under an extremely low interest rate condition. In light of Abenomics, Japan's comprehensive policy approach, the most powerful "arrow"7 is an aggressive monetary easing, which decreases the interest rate to the zero lower bound. However, as the interest rate falls even lower, the velocity also declines and approaches one. In addition, starting from February 2016, the Bank of Japan introduced a negative interest rate policy, which consequently clears the zero lower bound restriction relating to this formula.

\subsection{The Modified AS-AD Equilibrium}

To obtain the modified AS-AD equilibrium, we first remove the assumption $P_{t}^{e}=P_{t-1}$ to transform (9). The resulting AS curve becomes:

$$
\begin{gathered}
\pi_{t}=\log m+\log P_{t}^{e}-\log P_{t-1}+\log Y_{t}+(\alpha- \\
1) \log G_{t}+\log E_{t .}
\end{gathered}
$$

Then, using (13), the modified AS curve, in conjunction

7 Abenomics consists of three so-called "arrows": aggressive monetary easing, flexible fiscal policy, and structural reform. 
with (12), the AD curve, we can obtain the solutions of the model as follows:

$$
\begin{aligned}
& \log Y_{t}^{*}=1 / 2\left[\log M_{t}-\log m-\log P_{t}^{e}-(\alpha-1) \log G_{t}-\log E_{t}\right], \\
& \pi_{t}^{*}=1 / 2\left[\log M_{t}+\log m+\log P_{t}^{e}+(\alpha-1) \log G_{t}+\log E_{t}\right]-\log P_{t-1} .
\end{aligned}
$$

This set of equations determines the modified AS-AD equilibrium. Equation (14) shows the equilibrium output and (15) shows the equilibrium inflation. Consider the case where $\alpha>1$ holds. Recall that $\alpha$ is an external accelerator which governs the magnitude of $G_{t}^{\alpha}$ (the productivity-based factor in the real wage-setting function), which determines the real wage rate. Recall also the modified Phillips curve expressed as (13).

From (13) (the modified AS curve), we find that if $\alpha>1$ holds, the productivity coefficient will become positive. This is consistent with our seemingly contradictory findings in Table 1. Next, consider an economic state in which $\alpha>1$ holds for (15). In this case, the equilibrium level of inflation will likely be positive. Finally, confirm whether output at the modified AS-AD equilibrium could expand. Equation (14) shows that where $\alpha>1$ holds, productivity growth lowers the equilibrium level of the output, but we could avoid this if the money supply grew. This policy, which ensures a larger $\log M_{t}$, means both equilibrium output and equilibrium inflation will be positive. This is why our findings suggest the decisive role of monetary policy to ensure the unconstrained effects on output growth.

In these equations, $\alpha$ governs the acceleration of real wage growth. If $\alpha>1$ holds, then acceleration is expected. If $\alpha<1$ holds, then acceleration does not take place. As we can explain our contradictory findings with $\alpha>1$, then the seemingly contradictory results cited earlier in Table 1 are recognizable as fitting the modified theory, and therefore no longer contradictory. Moreover, this indicates that postwar acceleration of productivity-based real wage inflation existed in the first part of our sample period. This contrast with the second period, which is explained by $\alpha<1$. No acceleration arises after the bubble economy burst, and this is revealed by the negative productivity coefficient in Table 1. We can ascribe that difference, at least according to our theory, to $\alpha$, which suggests that much of the slowdown in Japanese inflation is because of the lack of the postwar acceleration of productivity-based real wage inflation.

\section{Conclusions}

We have shown that a modified Phillips curve, which includes one of the missing elements of the standard Phillips curve (real wage behavior) in an implicit form, can explain Japanese inflation-unemployment dynamics over a 40 -year period. The modified theory, in conjunction with a quantity equation with zero velocity, proved the simplest economic framework for representing the behavior of
Japanese economy in response to shocks and government policies (particularly monetary policy). This framework, or the modified AS-AD equilibrium we identified, shifts the emphasis of the aggregate economy from the pure supply side (see, Ashiya [13]) to its interaction with the demand side, although the focus is still on the supply side of the economy and the specification of the $\mathrm{AD}$ curve is drastically simplified.

We conclude that much of the slowdown in Japanese inflation has been because of the lack of the postwar acceleration of productivity-based real wage inflation unexplained within a traditional demand-oriented formula. We could reasonably expect the existence of this factor in a booming economy to place upward pressure on actual price inflation. However, this becomes more difficult in a mature economy as exists in Japan in recent decades. Consequently, the role of external economic policy to affect price expectations becomes more important. The main implication for policymakers is the need for money growth to secure the unconstrained effect on the output, which is consistent with the "first arrow" of Abenomics, Japan's comprehensive policy approach.

Some may argue that part of the efficacy of the productivity-based real wage acceleration that we identified is related to the use of the simpler formulation of the $\mathrm{AD}$ curve, which has an inherent analytical bias supporting the role of monetary policy. However, it is permissible given the focus on the decisions of suppliers. The lower the rate of interest is, the lower the velocity becomes, all else being equal. This is consistent with our setting of zero velocity in the analysis of Japan's deflationary economic state as the Japanese central bank now keeps the policy rate near zero. Practically, this primary factor exerts upward drift on the Phillips curve, a feature contrasting with Akerlof's et al. [25] formulation of the Phillips curve, which specifies the shift in expected unit labor costs arising from downward wage rigidity. Moreover, our estimation results (Table 2) provide evidence that support our finding that upward flexibility in the real wage rate, and its acceleration along with productivity growth, is the solution to Japan's deflationary problem. This counters critics arguing our primary factor of productivity-based real wage acceleration is problematic. Although the historical data varies, the general trend is upward during our first sample period, especially close to periods of rapid growth.

It is an open question whether money growth or monetary policy is effective in bringing inflation up to the target level. Sims's [27] idea of the use of fiscal policy when the economy suffers from extremely low or negative inflation inspired the fashion of Abenomics (Hamada [28]). We ignore this aspect of the underlying modified AS-AD model in this analysis. A more detailed specification of the AD side of the economy, e.g., at least including government expenditures, is necessary before any concrete recommendations on how to address the deflationary problem in Japan.

There is a further question of whether the real wage moves 
cyclically under the assumption of diminishing returns. Our approach is to set an exogenous productivity-related real wage accelerator. The volatility of the accelerator, or whether its value is greater than one, is thought to be dependent on the trend or phase (boom or not) of the economy. This is consistent with Hamada and Kurosaka's [10] findings on the link between the economic state and the trend in the change of the real wage rate. The puzzle that relates to Okun's coefficient can also provide an explanation of this as its value generally exceeds one as expected, which is consistent with increasing returns. Note that the conventional setting with diminishing returns would not support the implication of Okun's law. Thus, a remaining issue is to elucidate the contradictions between commonly held economic law and conventional theoretical issues; part of this could be the calculation of the Okun coefficient and its resulting volatility.

Finally, our analysis of the deflationary state in Japan has a direct bearing on the reduced form, triangular Phillips curve literature that examines the dynamics of the inflation-unemployment relationship. As in Gordon [1], we treat the productivity variable as a Dew-Becker and Gordon-type productivity variable [3]: the value of the productivity trend growth acceleration being equal to the
Hodrick-Prescott filter of the productivity growth trend with that trend eight quarters earlier. This evolution of the productivity variable has led us to posit our modified AS-AD theory based on a modified supply-side analysis.

\section{Acknowledgements}

I am very grateful to Professor Koichi Hamada for the valuable comments on the insights of my original report, and Professor Kenji Miyazaki for his generous help in furthering the range and depth of my analysis. I would also like to thank the editor and the anonymous referees for their insightful comments and correspondence.

\section{Appendix A. Estimates of the Phillips Curve Equation (Time-Varying NAIRU Setting), Model A1}

Table A1 provides the estimation results of the Phillips curve with a time-varying NAIRU using Model A1. The specification is next to Fig. A1.

Table A1. The Phillips Curve Equation (Time-Varying NAIRU Setting), Model A1, 1972:Q1 to 2014:Q4

\begin{tabular}{|c|c|c|c|c|c|c|c|c|c|}
\hline \multirow[t]{2}{*}{ Variable } & \multirow[t]{2}{*}{ Lags } & \multicolumn{3}{|c|}{ 1972:Q1-1991:Q4 } & & \multicolumn{4}{|c|}{ 1992:Q1-2014:Q4 } \\
\hline & & Japan & & U.S. & & Japan & & U.S. & \\
\hline Constant & & $0.118(0.1)$ & & $1.286(1.9)$ & $*$ & $-0.050(0.3)$ & & $0.419(2.1)$ & $* *$ \\
\hline Lagged Dependent Variable & 1 & $0.997(11.5)$ & $* * *$ & $1.108(10.0)$ & $* * *$ & $-0.050(4.6)$ & $* * *$ & $0.992(10.1)$ & $* * *$ \\
\hline Lagged Dependent Variable & 2 & $-0.006(0.0)$ & & $-0.290(1.8)$ & $*$ & $-0.051(0.1)$ & & $-0.013(0.1)$ & \\
\hline Lagged Dependent Variable & 3 & $0.121(0.5)$ & & $0.116(0.7)$ & & $-0.052(0.2)$ & & $-0.110(0.8)$ & \\
\hline Lagged Dependent Variable & 4 & $-0.278(2.0)$ & $* *$ & $-0.093(0.9)$ & & $-0.053(0.9)$ & & $0.001(0.0)$ & \\
\hline Unemployment Gap & 0 & $-1.058(1.6)$ & $* *$ & $-0.154(2.3)$ & $* *$ & $-0.054(1.4)$ & & $-0.032(1.7)$ & $*$ \\
\hline Productivity Trend Change & 0 & $0.134(2.9)$ & $* * *$ & $0.106(6.0)$ & $* * *$ & $-0.055(5.9)$ & $* * *$ & $0.099(26.8)$ & $* * *$ \\
\hline Energy Effect & 0 & $4.814(0.4)$ & & $-19.476(1.4)$ & & $-0.056(0.0)$ & & $-3.975(1.4)$ & \\
\hline Energy Effect & 1 & $-0.094(1.6)$ & & $-0.113(3.9)$ & $* * *$ & $-0.057(2.6)$ & $* * *$ & $-0.093(7.9)$ & $* * *$ \\
\hline Energy Effect & 2 & $-0.100(2.1)$ & $* *$ & $0.063(2.5)$ & $* *$ & $-0.058(0.1)$ & & $0.005(0.3)$ & \\
\hline Energy Effect & 3 & $0.078(2.5)$ & $* *$ & $-0.018(1.1)$ & & $-0.059(0.7)$ & & $0.010(0.8)$ & \\
\hline Unemployment Gap in Final & State & $-0.242(1.5)$ & & $-0.049(0.1)$ & & $-0.060(3.3)$ & $* * *$ & $0.637(0.9)$ & \\
\hline NAIRU in Final State & & $2.318(15.6)$ & $* * *$ & $7.152(20.5)$ & $* * *$ & $-0.061(17.9)$ & $* * *$ & $5.053(7.7)$ & $* * *$ \\
\hline Log Likelihood & & -45.91 & & -105.24 & & 10.08 & & -18.42 & \\
\hline Akaike Info Criterion & & 1.50 & & 2.98 & & 0.09 & & 0.70 & \\
\hline Schwarz Criterion & & 1.91 & & 3.40 & & 0.47 & & 1.09 & \\
\hline Hannan-Quinn Criterion & & 1.66 & & 3.15 & & 0.24 & & 0.86 & \\
\hline
\end{tabular}

Notes: Estimated by maximum likelihood (Marquardt). z-statistics in parentheses. *, **, and *** indicate the coefficient or sum of coefficient is statistically significant at the 10,5 , or 1 percent level, respectively. The coefficients of the lagged dependent variable and energy effect variable are estimated separately in the state space. The variance of the NAIRU fixed at 0.001 . It is well known that the size of this variance affects the estimation results, and this is why we only present these outputs as an additional source. See, e.g., Laubach [8], who estimates the time-varying NAIRU models in a similar context by setting those variances at, e.g., 0.026 (for the U.K.), 0.006 (for Germany), or even zero (for Canada, Australia, France, and Italy), and so on. Gordon's [1] productivity variable was found to fit very well at the 1 percent level both the U.S. and Japanese data, although the robustness of the results could not be confirmed for the Japanese estimates. 


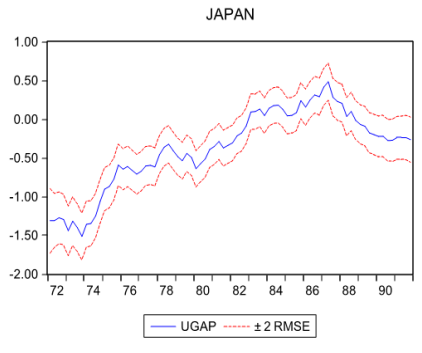

JAPAN
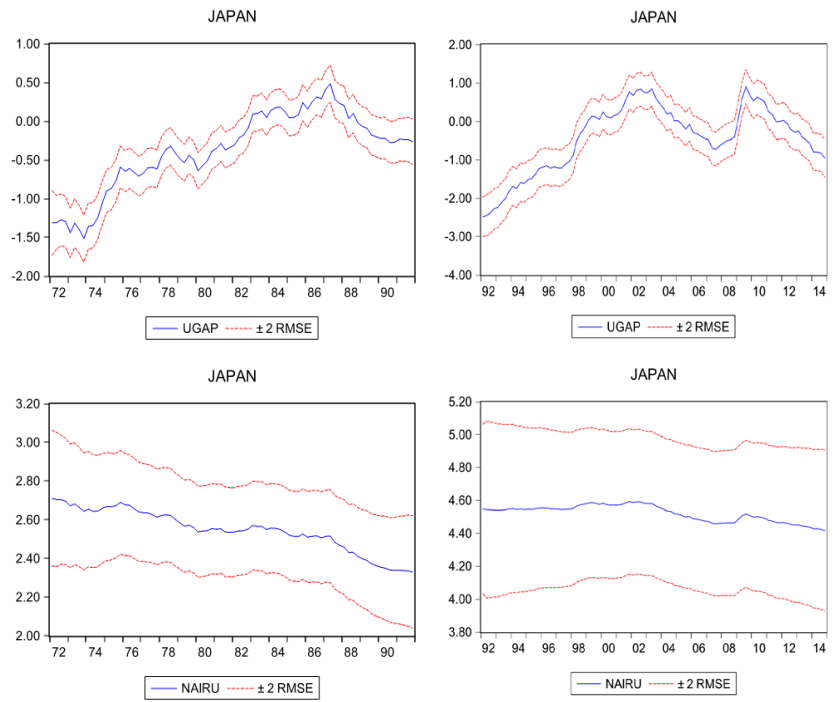

JAPAN

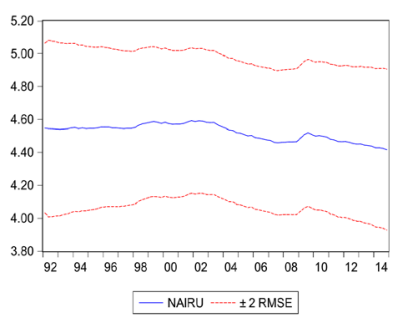

U.S

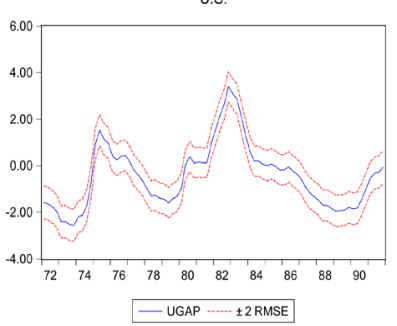

U.S

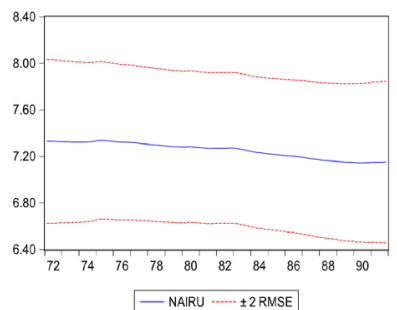

U.S

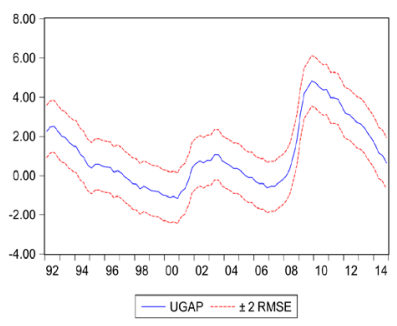

U.S.

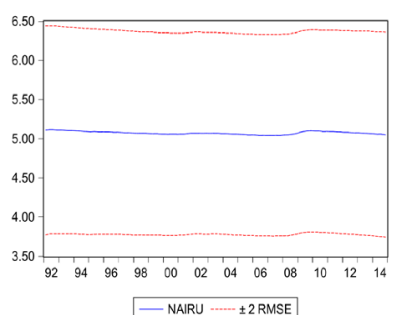

Figure A1. The State Estimation of the Unemployment Gap and NAIRU Estimates

We use the Kalman filter technique to estimate our Phillips curve model with time-varying NAIRU setting. Equation (3) specified above is the price Phillips curve, which works as the signal equation. The following set of equations (A1), (A2) and (A3) yields the specification of the time-varying NAIRU:

$$
\begin{aligned}
& U_{t}=U_{t}^{N}+U G A P_{t}, \\
& U_{t}^{N}=U_{t-1}^{N}+\varepsilon_{t}^{U^{N}} \\
U G A P_{t}= & \rho U G A P_{t-1}+\varepsilon_{t}^{U G A P},|\rho|<1,
\end{aligned}
$$

where $U G A P_{t}$ denotes the unemployment gap, and $\varepsilon_{t}^{U^{N}}$ and $\varepsilon_{t}^{U G A P}$ are the error terms that follow a zero-mean stationary process. Equation (A1) is the signal equation, and (A2) and (A3) are the state equations.

To obtain this model, we follow the common specifications widely used in the Phillips curve literature. First, we define the movement of the NAIRU, $U_{t}^{N}$, which is an unobserved component, as a random walk without drift, expressed as (A2). We also define the gap between the unemployment rate and the NAIRU, or the unemployment gap, $U_{t}-U_{t}^{N}$, as a stationary AR (1) series, expressed as (A3). We also adopt Watson's [2] decomposition of the observed series, $U_{t}$, as in (A1).

Concerning the Kalman filter technique, see, e.g., Gordon [16] or Staiger et al. [29]. This technique is less restrictive and therefore preferred compared to other approaches (Richardson et al. [4]). For an alternative HPMV filter approach see, e.g., Laxton and Tetlow [30], and Boone [31].
See, e.g., Ebeke and Everaert [32] for stable specification of the time-varying NAIRU model; concerning the NAIRU specification in this context, see, e.g., King et al. [33], Staiger et al. [29], and Gordon [16]. Laubach [8] shows that calculations with or without drift do not affect the performance of the NAIRU estimates, even if a country has an unemployment rate with an upward trend.

We extended our time-varying NAIRU model to provide more information on the specification of the NAIRU. That is, we tried adding drift or the delta of the NAIRU as explanatory variables, or the change of the specification of the unemployment gap - which reflects Okun's relation and the corresponding demand-side shocks that represent business cycle fluctuations. However, these attempts still provided unsatisfactory results in terms of the limited variance of the NAIRU movements.

\section{Appendix B. Estimates of Okun's Coefficient}

Table A2 summarizes the estimation results for Okun's coefficient. We employ the simplest relationship between the change in unemployment rates and the change in GDP, namely, GDP growth to obtain these values. This simplification does not change the nature of the analysis, but makes it possible to confirm our general understanding of Okun's law. 
Table A2. The Okun Coefficient

\begin{tabular}{|c|c|c|c|c|c|}
\hline \multicolumn{2}{|c|}{$1972-1991$} & \multicolumn{2}{|c|}{$1992-2014$} & \multicolumn{2}{|c|}{$\begin{array}{c}\text { All period } \\
1972-2014\end{array}$} \\
\hline Japan & U.S. & Japan & U.S. & Japan & U.S. \\
\hline 25.780 & 2.403 & 7.923 & 2.309 & 21.115 & 2.420 \\
\hline
\end{tabular}

Notes: Calculated using the estimation results of $\Delta U_{t}=\alpha+\beta \Delta G D P_{t}+\varepsilon_{t}$ (Table A3). The simplest way to arrive at the Okun coefficient is by using these estimation results to obtain the value of $-(1 / \beta)$. The level and volatility of the Okun coefficients could be the source of the upward shift of the wage-setting function.

Table A3. The Simplest Source for the Okun Coefficient

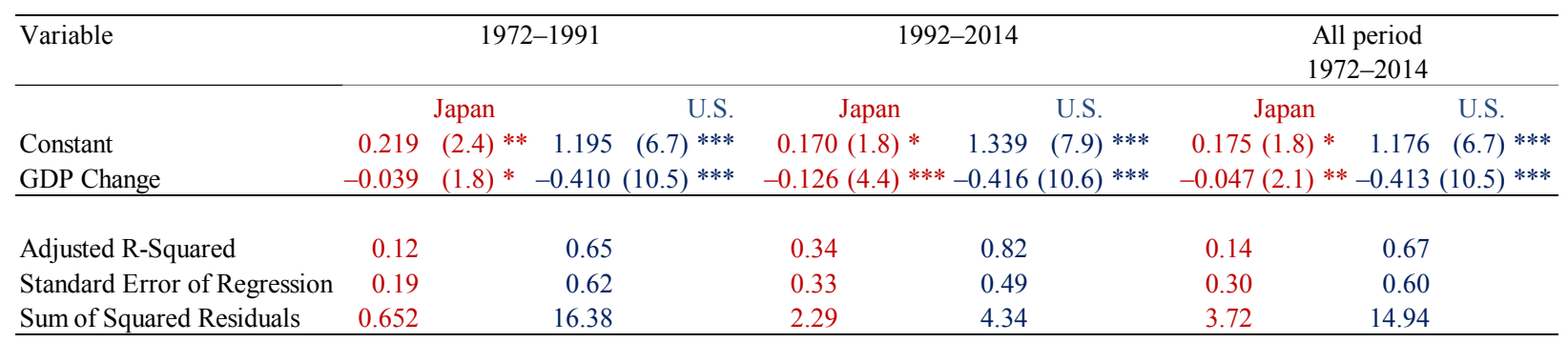

Notes: OLS estimates with HAC standard errors and covariance. The level and volatility of the Okun coefficients could be the source for the upward shift of the wage-setting function. t-statistics in parentheses. $* * *$, and *** indicate the coefficient or sum of coefficients is statistically significant at the 10,5 , or 1 percent level, respectively. The results are for the simplest calculation of the Okun coefficient. The dependent variable is the change in the unemployment rate.

\section{REFERENCES}

[1] R. J. Gordon. The Phillips Curve is Alive and Well: Inflation and the NAIRU during the Slow Recovery. NBER Working Paper, No.19390, 1-54, 20, 2013.

[2] M. W. Watson. Inflation Persistence, the NAIRU, and the Great Recession, American Economic Review, Vol.104, No.5, 31-36, 2014.

[3] I. Dew-Becker, R. J. Gordon, Where Did the Productivity Growth Go? Inflation Dynamics and Distribution of Income, NBER Working Paper, No.11842, 1-86, 2005.

[4] P. Richardson, L. Boone, C. Giorno, M. Meacci, D. Rae, D. Turner. The Concept, Policy Use and Measurement of Structural Unemployment: Estimating a Time Varying NAIRU across 21 OECD Countries, OECD Economics Department Working Papers, No.250, 1-75, 2000.

[5] S. Guichard, E. Rusticelli. Reassessing the NAIRUs after the Crisis, OECD Working Paper, No.918, 1-27, 2011.

[6] F. Nishizaki. The NAIRU in Japan: Measurement and its Implications, OECD Working Paper, No.173, 1-18, 1997.

[7] M. Apel, P. Jansson. A Parametric Approach for Estimating Core Inflation and Interpreting the inflation process, Working Paper Series from Sveriges Riksbank (Central Bank of Sweden), No.80, 1-22, 1999.

[8] T. Laubach. Measuring the NAIRU: Evidence from Seven Economies, Review of Economics and Statistics, Vol.83, No.2, 218-231, 2001.

[9] R. E. Lucas. Some International Evidence on Output-Inflation Tradeoffs, American Economic Review, Vol.63, No.3, 326-334, 1973.

[10] K. Hamada, Y. Kurosaka. Trends in Unemployment, Wages

and Productivity: The Case of Japan, Economica, Vol.53, No.210, S275-96, 1986.

[11] S. Kuroda, I. Yamamoto. Is Downward Wage Flexibility the Primary Factor of Japan's Prolonged Deflation? Asian Economic Policy Review, Vol.9, No.1, 143-158, 2014.

[12] K. Nishizaki, T. Sekine, Y. Ueno. Chronic Deflation in Japan, Asian Economic Policy Review, Vol.9, No.1, 20-39, 2014.

[13] N. Ashiya. A Possible Answer to Japan's Deflationary Problem as Revealed by the Use of a Modified Phillips Curve, and an Explanation of Some Seemingly Contradictory Results, Proceedings of the 7th Indonesia Japan Joint Scientific Symposium, 195-204, 2016.

[14] N. Sudo, K. Ueda, K. Watanabe. Micro Price Dynamics during Japan's Lost Decades, Asian Economic Policy Review, Vol.9, No.1, 44-64, 2014.

[15] S. Urasawa. Japan's Deflation: The Role of Wage Costs, Applied Economic Letters, Vol.21, No.11, 742-746, 2014.

[16] R. J. Gordon. Can the Inflation of the 1970s Be Explained? Brookings Papers on Economic Activity, No.1, 253-277, 1977.

[17] R. J. Gordon. Inflation, Flexible Exchange Rates, and the Natural Rate of Unemployment, In: Martin N. Baily, ed., Workers, Jobs, and Inflation, Washington: Brookings, 88-152, 1982.

[18] P. R. Krugman. It's Baaack: Japan's Slump and the Return of the Liquidity Trap, Brookings Papers on Economic Activity, No.2, 137-187, 1998.

[19] U.S. Department of Labor, Bureau of Labor Statistics. International Comparison of Unemployment, Washington, D.C., 1979.

[20] E. Shiraishi. Shitsugyo gainen no kokusai hikaku-Nichibei hikaku o chushin toshite [Comparison between the Japanese and the U.S. Concept of Unemployment] (in Japanese). Monthly Labor Statistics and Research Bulletin, Vol.34, No.3, 
13-20, 1982.

[21] K. Hamada, Y. Kurosaka. The Relationship between Production and Unemployment in Japan: Okun's Law in Comparative Perspective. European Economic Review, Vol.25, No.1, 71-94, 1984.

[22] Y. Cao, A. Shapiro. Will inflation Remain Low? Federal Reserve Bank of San Francisco Economic Letter, No.2014-19, $1-5,2014$.

[23] O. Blanchard, J. Gali. Labor Markets and Monetary Policy: A New Keynesian Model with Unemployment, American Economic Journal: Macroeconomics, Vol.2, No.2, 1-30, 2010.

[24] M. Bruno. Raw Materials, Profits, and the Productivity Slowdown, Quarterly Journal of Economics, Vol.99, No.1, $1-29,1984$

[25] G. A. Akerlof, G. L. Perry, W. T. Dickens. The Macroeconomics of low inflation, Brookings Papers on Economic Activity, No.1, 1-76, 1996.

[26] N. G. Mankiw. Comments in Akerlof et al. See above [25], 66-70, 1996.

[27] C. A. Sims. Fiscal Policy, Monetary Policy and Central Bank Independence, Proceedings of Jackson Hole Economic Symposium, Federal Reserve Bank of Kansas City, 313-325, 2016.
[28] K. Hamada. Keizai Seisaku no Aratana Paradigm wo Kataru-FTPL no Framework-Kinyu Zaisei no Kumiawase de Abenomics no Arata na Shinka he [Talk on the New Paradigm of Abenomics based on FTPL] (in Japanese), Gekkan Shihon Shijo, No.377, 10-22, 2017.

[29] D. Staiger, J. H. Stock, M. W. Watson. How precise are estimates of the Natural Rate of Unemployment? In: C. D. Romer and D. H. Romer (eds.), NBER Studies in Business Cycles, Vol.30, Chicago: University of Chicago Press, 195-242, 1997.

[30] D. Laxton, R. Tetlow. A Simple Multivariate Filter for the Measurement of Potential Output, Bank of Canada Technical Report, No.59, 1-46, 1992.

[31] L. Boone. Comparing Semi-Structural Methods to Estimate Unobserved Variables, OECD Economics Department Working Paper, No.240, 1-27, 2000.

[32] C. Ebeke, G. Everaert. Unemployment and Structural Unemployment in the Baltics. IMF Working Papers, No.14/153, 1-25, 2014.

[33] R. G. King, J. H. Stock, M. W. Watson. Temporal Instability of the Unemployment-Inflation Relationship, Economic Perspectives of the Federal Reserve Bank of Chicago, Vol. May/June, 2-12, 1995. 